\title{
SURVEI PENINGKATAN MUTU BERKELANJUTAN MELALUI PEMANTAUAN DAN PENGUKURAN KEPUASAN PEMUSTAKA
}

\author{
Fransisca Rahayuningsih*
}

\begin{abstract}
Two keywords in implementing Quality Management System 1SO 9001:2008 are customer satisfaction and continuous improvement. Both are important and always influence each other. In the practice of library service, user satisfaction becomes an essential aspect for the library to make a continuous improvement. This means when a library puts priority on user satisfaction, it will make continuous improvement. In other words, a continuous improvement will always be made when the library concentrates on achieving user satisfaction. This study is aimed at identifying the achievement level of user satisfaction reached at Sanata Dharma University Library (SDUL) in the periodof 2008 to 2014 and to find out continuous improvement that has been made by SDUL, especially, the result analysis on monitoring and assessing user satisfaction. This study was a survey that used descriptive. method. The result of the study showed the achievement level of monitoring and assessmentof user satisfaction at SDUL in the period of 2008 to 2014 reached maximum score, that is, 3.5 to 3.8 in the scale of 1 to 5 . Observed from the user satisfaction analysis, continuous quality improvement conducted in SDUL covered three important fields, that is, information and information access facilities, library services, and infrastucture and work environment.
\end{abstract}

Keywords: library user satisfaction, collection and information access, library services, infrastructure andwork environment

*Pustakawan Universitas Sanata Dharma Yogyakarta

A. PEndahuluan

1. Latar Belakang

Perpustakaan yang dikelola dengan baik akan menentukan kepuasan pemustaka. Perpustakaan Universitas Sanata Dharma (PUSD) berkomitmen untuk memberikan kepuasan kepada pemustaka, sebagai sebuah konsekuensi dari implementasi Sistem Manajemen Mutu (SMM) ISO 9001:2008. Implementasi SMM ISO di PUSD dilakukan sejak tahun 2008 hingga sekarang. Dalam implementasi tersebut, fokus kepada pemustaka dan peningkatan terus menerus menjadi prioritas utama. Fokus kepada pemustaka dan peningkatan terus menerus, dilakukan salah satunya melalui penetapan sasaran mutu terkait dengan kepuasan pemustaka. Kepuasan pemustaka selanjutnya diukur dan dipantau menggunakan pedoman yang telah ditetapkan. Gerson (2002), manyampaikan bahwa pengukuran kepuasan dilakukan untuk (1) Mempelajari persepsi pelanggan, (2) Menentukan kebutuhan, keinginan, persyaratan, dan harapan pelanggan, (3) Menutup kesenjangan, (4) Memeriksa apakah peningkatan mutu pelayanan dan kepuasan pelanggan sesuai harapan Anda atau tidak, (5) Mempelajari bagaimana Anda melakukan dan apa yang harus dilakukan kemudian, (6) menerapkan proses perbaikan berkesinambungan. Lebih lanjut Gerson (2002) menyatakan bahwa "manfaat utama dari program pengukuran adalah tersedianya umpan balik yang segera, berarti, dan objektif. Dengan hasil pengukuran orang bisa melihat bagaimana mereka melakukan pekerjaannya, membandingkannya dengan standar kinerja, dan memutuskan apa yang harus dilakukan untuk melakukan perbaikan berdasarkan pengukuran tersebut".

Sementara jika diimplementasikan ke perpustakaan, Rahayuningsih (2015) menyampaikan manfaat pengukuran kepuasan pemustaka adalah:

1. Pengukuran kepuasan pemustaka menyebabkan orang memiliki rasa berhasil dan berprestasi yang kemudian diterjemahkan menjadi pelayanan yang prima kepada pemustaka.

2. Pengukuran bisa dijadikan dasar menentukan standar kinerja dan standar prestasi yang harus dicapai, yang akan mengarahkan menuju mutu yang semakin baik dan kepuasan pemustaka meningkat. 
3. Pengukuran memberikan umpan balik segera kepada perpustakaan, terutama bila pemustaka sendiri yang mengukur kinerja perpustakaan.

4. Pengukuran memberi tahu kepada perpustakaan apa yang harus dilakukan untuk memperbaiki mutu dan kepuasan pemustaka serta bagaimana harus melakukannya. lnformasi ini juga bisa datang langsung dari pemustaka.

5. Pengukuran memotivasi orang untuk melakukan dan mencapai tingkat produktivitas yang tinggi.

Kepuasan pemustaka tentu akan menjadi tanggungjawab semua pihak di perpustakaan dari Top Manajemen sampai pada level paling bawah.

PUSD pada awalnya memiliki 9 sasaran mutu, selanjutnya berkembangan menjadi 11 sasaran mutu, dan pada tahun 2015 ini dikembangkan menjadi 17 sasaran mutu. Salah satu sasaran mutu yang dimiliki adalah Sasaran Mutu Kepuasan Pemustaka. PUSD melakukan pemantauan dan pengukuran sasaran mutu kepuasan pemustaka setiap 6 bulan sekali pada bulan Februari/Maret dan bulan September. Pemantauan dan pengukuran kepuasan pemustaka dilakukan berdasarkan standar operating procedure yang baku, yaitu Prosedur Pemantauan dan Pengukuran (820/P/001), yang di dalamnya terdiri dari Instruksi Kerja Pemantauan dan Pengukuran Rerata Kepuasan Pemustaka (820/L/008), Kuesioner Kepuasan Pengguna (820/D/001), Pedoman Pengukuran dan Pemantauan Rerata Kepuasan Pengguna (820/D/009), dan Formulir Rekapitulasi Pengukuran Rerata Kepuasan Pengguna $(820 / F / 012)$. Metode dalam pemantauannya adalah dengan cara mengedarkan kuesioner kepada pengguna perpustakaan dengan jumlah sampel ditentukan menggunakan Tabel Isaac dan Michael, di mana rata-rata jumlah sampelnya adalah minimal 289 setiap kali pengukuran. Pertanyaan dalam kuesioner terdiri dari 20 butir yang diadopsi dari butir-butir pertanyaan pada standar ISO 11620 mengenai Pengukuran Kinerja Perpustakaaan (performance indicator). Dalam butir pertanyaan terebut terdiri dari 3 hal pokok, yaitu menyangkut (1) informasi dan sarana akses informasi, (2) pelayanan perpustakaan, (3) infrastruktur dan lingkungan kerja. Selama pemantauan dan pengukuran yang dilakukan PUSD sejak tahun 2008 s.d. 2014 telah dilakukan 13 kali pengukuran dengan hasil yang masih naik turun berkisar antara 3,5 s.d. 3,8 .
2. Permasalahan Penelitian

Berdasarkan latar belakang masalah di atas, maka permasalahan dalam penelitian ini yaitu bagaimana tingkat ketercapaian kepuasan pemustaka dan apa saja peningkatan berkelanjutan yang dilakukan di Perpustakaan Universitas Sanata Dharma tahun 2008-2014.

\section{Tujuan Penelitian}

Tujuan penelitian ini adalah untuk mengetahui tingkat ketercapaian kepuasan pemustaka dan peningkatan berkelanjutan yang dilakukan di Perpustakaan Universitas Sanata Dharma tahun 2008-2014.

\section{B. TINJAUAN PUSTAKA}

\section{Kepuasan Pemustaka}

Di perpustakaan, kepuasan pemustaka merupakan pintu gerbang menuju peningkatan berkelanjutan. Kepuasan pemustaka sangat dipengaruhi oleh faktor-faktor yang kasat mata maupun tidak kasat mata, serta ragam pelayanan yang berhubungan dengan kinerja dan kepedulian. Faktor kasat mata terdiri dari kinerja, kualitas, keandalan dan biaya. Sedangkan faktor yang tidak kasat mata seperti rasa kepedulian, sopan santun, kesediaan untuk membantu, kemampuan untuk memecahkan masalah.

Pada dasarnya mewujudkan kepuasan pemustaka bukanlah hal yang mudah untuk memenuhinya karena kepuasan pemustaka memiliki faktor yang dapat mendukung pemanfaatan jasa layanan yang disediakan. Adapun faktor yang mendukung dalam mendapatkan kepuasan pemustaka menurut Pedoman Umum Penyelenggaraan Perpustakaan Perguruan Tinggi, (2004) dapat diperhatikan ketentuan berikut:

1. Berorientasi pada kebutuhan dan kepentingan pengguna.

2. Diberikan kepada pengguna atas dasar keseragaman, keadilan, dan kemerataan.

3. Dilaksanakan secara optimal dan didasari oleh peraturan yang jelas.

4. Dilaksanakan secara cepat, tepat dan mudah melalui cara yang teratur, terarah dan cermat.

Sementara mengadopsi dari Keputusan Menteri Pendayagunaan Aparatur Negara Nomor: 63 Tahun 2003 tentang pelayanan publik, maka kepuasan pemustaka akan tercapai apabila pelayanan kita menganut asas: kesederhanaan; kejelasan; kepastian waktu; akurasi; produk pelayanan publik diterima 
dengan benar, tepat dan sah; keamanan; tanggung jawab; kelangkapan sarana dan prasarana; kemudahan akses; kedisiplinan, kesopanan dan keramahan; kenyamanan.

\section{Informasi dan Sarana Akses Informasi}

Di perpustakaan, informasi dan sarana akses informasi menjadi hal yang harus diprioritaskan. Informasi dan sarana akses informasi harus disediakan melalui perencanaan yang baik. Perpustakaan harus melakukan kajian terhadap kebutuhan informasi, dan melakukan desain dalam pengembangan sarana akses informasi sehingga kepuasan pemustaka dapat benar-benar tercapai.

Rahayuninsih (2015) menyatakan bahwa ketersediaan informasi dan akses informasi yang berkualitas, terdiri dari aspek Scope, Convenience, Easy of Navigation, Timelines, Equipment dan Self Reliance. Scope (Cakupan Informasi), yaitu menyangkut tentang ketersediaan koleksi yang memadai, kekuatan koleksi yang dimiliki, cakupan isi. Convenience, yaitu kenyamanan pemustaka dalam mengakses informasi, yaitu terkait dengan kenyaman pemustaka mengakses informasi tanpa harus datang ke perpustakaan dan kejelasan petunjuk dalam pelayanan. Ease of Navigation, yaitu kemudahan pemustaka untuk mengakses informasi yang dimiliki oleh perpustakaan baik melalui katalog digital maupun langsung pada jajaran rak koleksi. Timeliness, adalah kecepatan pemustaka untuk mengakses informasi, yang mana sangat didukung oleh kesesuaian data pada katalog digital dengan data koleksi di jajaran rak, keteraturan susunan koleksi di rak. Equipment, yaitu peralatan pemustaka untuk mengakses informasi, dalam hal ini adalah kecukupan jumlah komputer penelusuran dan kecepatan fasilitas hotspot untuk mengakses informasi. Self Reliance adalah kepercayaan diri dari pemustaka dalam memanfaatkan fasilitas perpustakaan, yaitu bagaimana pemustaka memiliki keyakinan secara mandiri untuk melakukan akses informasi baik menggunakan komputer penelusuran maupun mencari koleksi langsung pada jajaran rak.

\section{Pelayanan Perpustakaan}

Pelayanan perpustakaan menjadi ujung tombak di perpustakaan. Perpustakaan dikatakan baik secara keseluruhan apabila pelayanan yang diberikan kepada pemustaka memuaskan, namun pelayanan perpustakaan dikatakan tidak baik apabila salah satu dalari aspek pelayanan tidak dapat memuaskan kebutuhan pemustaka.
Rahayuningsih (2015) menyatakan bahwa kemampuan petugas perpustakaan dalam melayani pemustaka yang terdiri dari aspek empathy, responsiveness, assurance dan reliability. Empathy yaitu rasa peduli dan memberi rasa penuh perhatian kepada setiap individu pengguna. Responsiveness, selalu siap/tanggap membantu pengguna yang kesulitan dan selalu membuka diri untuk membantu. Assurance, yaitu pengetahuan, wawasan, kemampuan dan keramahan pustakawan/petugas perpustakaan dalam melayani pengguna. Reliability, yaitu kemampuan memberikan janji dan harapan dalam pelayanan dan menepatinya secara tepat dan akurat.

\section{Infrastruktur dan Lingkungan Kerja}

Infrastruktur dan lingkungan kerja di perpustakaan menentukan kenyamanan pemustaka dalam memanfaatkan perpustakaan. Perpustakaan harus mengupayakan agar infrastruktur dapat didesain sedemikian rupa sehingga membuat pemustaka bertahan lama untuk belajar dan bereksplorasi di perpustakaan. Hal ini tentunya juga harus didukung oleh kenyamanan ruang perpustakaan.

Rahayuningsib (2015) menyatakan bahwa ketersediaan fasilitas dan ruang yang bermanfaat bagi aktivitas pembelajaran pemustaka di perpustakaan yang terdiri dari aspek Tangibles, utilitarian space, symbol terms dan refuge. Tangibles (Bukti fisik), yaitu kemampuan perpustakaan dalam menampilkan sesuatu secara nyata berupa fasilitas fisik/gedung dan penampilan pustakawan yang menarik dan rapi. Utilitarian Space (Ruang yang bermanfaat), yaitu bahwa perpustakaan memiliki ruangan tenang yang mendukung belajar mandiri dan kelompok, selain itu perpustakaan memiliki desain ruang yang mampu menginspirasi belajar. Symbol Terms (berbagai makna), yaitu bahwa perpustakaan terbuka bagi seluruh sivitas akademika dan mampu menumbuhkan daya kreativitas mereka. Refuge, yaitu perpustakaan sebagai tempat belajar yang nyaman, dalam hal ini perpustakaan memiliki tempat tenang untuk belajar dan selalu dalam kondisi yang bersih.

\section{METODE PENELITIAN}

Penelitian ini dilakukan menggunakan metode deskriptif. Metode penelitian deskriptif menurut Whitney (1960) dalam Nazir (2005) adalah pencarian fakta dengan interpretasi yang tepat. Tujuan dari penelitian deskriptif adalah untuk 
membuat deskripsi, gambaran atau lukisan secara sistematis, faktual dan akurat mengenai fakta-fakta, sifat-sifat serta hubungan antarfenomena yang diselidiki. Jenis penelitian yang digunakan adalah metode survei.

\section{HASIL DAN PEMBAHASAN}

\section{Tingkat Ketercapaian Pemantauan Kepuasan Pemustaka PUSD}

Perpustak a $\mathrm{n}$ U S D s e la m a mengimplementasikan SMM ISO 9001:2008, memiliki sasaran mutu yang salah satunya adalah mengenai kepuasan pemustaka. Target dari sasaran mutu Kepuasan Pemustaka adalah 3,5 dari skala 1-5. Pemantauan sasaran mutu ini dilakukan secara kontinyu setiap 6 bulan sekali pada bulan Februari/Maret dan September. Berikut ini data mengenai periode pemantauan kepuasan pemustaka di PUSD.

Tabel 1. Periode Pemantauan Kepuasan Pemustaka

\begin{tabular}{cc}
\hline Tahun & Frekuensi \\
\hline 2008 & 1 \\
2009 & 2 \\
2010 & 2 \\
2011 & 2 \\
2012 & 2 \\
2013 & 2 \\
2014 & 2 \\
2015 & 2 \\
Total & $\mathbf{1 5}$ \\
\hline
\end{tabular}

Data primer di olah 2015

Berdasarkan tabel di atas dapat diketahui bahwa dari tahun 2008 PUSD melakukan pemantauan dan pengukuran kepuasan pemustaka sebanyak 1 kali, hal itu dikarenakan PUSD baru mulai mengimplementaskan SMM 1SO 9001:2008. Sedangkan sejak tahun 2009 sampai dengan tahun 2015, PUSD secara kontinyu melakukan pemantauan dan pengukuran kepuasan pemustaka setiap 6 bulan sekali, atau 2 kali dalam setahun.

Selanjutnya tabel berikut ditampilkan hasil pemantauan dan pengukuran kepuasan pemustaka selama kurun waktu tahun 2008 sampai dengan 2014.
Tabel 2. Hasil Pemantauan Kepuasan Pemustaka

\begin{tabular}{cccc}
\hline Tahun & \multicolumn{2}{c}{ Bulan } & Frekuensi \\
\cline { 2 - 3 } & Februri/Maret September & \\
\hline 2008 & 3,56 & 3,62 & 1 \\
2009 & 3,71 & 3,73 & 2 \\
2010 & 3,71 & 3,67 & 2 \\
2011 & 3,81 & 3,75 & 2 \\
2012 & 3,86 & 3,76 & 2 \\
2013 & 3,84 & 3,83 & 2 \\
2014 & Total & & $\mathbf{1 3}$ \\
\hline
\end{tabular}

Data primer di olah 2015

Berdasarkan tabel di atas diketahui bahwa hasil pemantauan dan pengukuran kepuasan pemustaka tahun 2008 adalah 3,62 dari skala $1-5$ berarti target tercapai. Hasil pemantauan dan pengukuran kepuasan pemustaka tahun 2009 adalah 3,56 dari skala 1-5 berarti pada bulan Februari dan 3,73 pada September target tercapai. Hasil pemantauan dan pengukuran kepuasan pemustaka tahun 2010 adalah 3,71 dari skala $1-5$ berarti pada bulan Februari dan 3,67 pada September target tercapai. Hasil pemantauan dan pengukuran kepuasan pemustaka tahun 2011 adalah 3,71 dari skala $1-5$ berarti pada bulan Maret dan 3,75 pada September target tercapai. Hasil pemantauan dan pengukuran kepuasan pemustaka tahun 2012 adalah 3,81 dari skala 1-5 berarti pada bulan Februari dan 3,72 pada September target tercapai. Hasil pemantauan dan pengukuran kepuasan pemustaka tahun 2013 adalah 3,86 dari skala $1-5$ berarti pada bulan Februari dan 3,76 pada September target tercapai. Hasil pemantauan dan pengukuran kepuasan pemustaka tahun 2014 adalah 3,84 dari skala 1-5 berarti pada bulan Februari dan 3,83 pada September target tercapai. Hasil keseluruhan tersebut bahwa pemantauan dan pengukuran sasaran mutu PUSD cenderung mengalami kenaikan.

Dua puluh (20) pertanyaan mengenai kepuasan pemustaka, terdapat 8 butir pertanyaan terkait informasi dan sarana akses informasi, 8 butir pertanyaan pelayanan perpustakaan dan 4 butir pertanyaan infrastruktur dan lingkungan kerja. 
1. Peningkatan Berkelanjutan dari Hasil Pemantauan Kepuasan Pcmustaka

Kucsioner yang diedarkan selain berisi pilihan angka menggunakan skala likert, juga berisi alasan dan masukan atas jawaban yang diberikan. Alasan dan masukan yang diberikan pemustaka menjadi titik pijak bagi perpustakaan untuk mendata di titik mana perpustakaan harus melakukan peningkatan berkelanjutan. Masukan-masukan tersebut dibawa dalam Rapat Koordinasi Tim Manajemen untuk menentukan tindak lanjutnya.
1.1 Peningkatan Terhadap Informasi dan Sarana Akses Informasi

Tabel di bawah ini memaparkan mengenai berbagai upaya peningkatan yang dilakukan perpustakaan USD terkait berbagai butir pertanyaan mengenai informasi dan sarana akses informasi.

Tabel. 3. Peningkatan Terhadap Informasi dan Sarana Akses Informasi

\begin{tabular}{|c|c|c|}
\hline No. & Butir Pertanyaan & Tindaklanjut \\
\hline 1 & $\begin{array}{l}\text { Kepuasan terhadap ketersediaan } \\
\text { judul buku }\end{array}$ & $\begin{array}{l}\text { 1) Membuat formulir usulan buku secara online } \\
\text { 2) Menambah judul- judul buku berdasarkan inisiatif } \\
\text { perpustakaan } \\
\text { 3) Mengadakan judul buku yang tidak dimiliki perpustakaan } \\
\text { dari hasil pemantauan sasaran mutu ketersediaan koleksi }\end{array}$ \\
\hline 2 & $\begin{array}{l}\text { Kepuasan terhadap ketersediaan } \\
\text { jumlah eksemplar buku }\end{array}$ & $\begin{array}{l}\text { 1) Menyediakan jumlah eksemplar buku sesuai dengan } \\
\text { dokumen Kebijakan Pengembangan Koleksi }(750 / \mathrm{D} / 101) \\
\text { 2) Menambahkan eksemplar buku pada buku yang tingkat } \\
\text { peminjamannya tinggi }\end{array}$ \\
\hline 3 & $\begin{array}{l}\text { Kepuasan terhadap koleksi } \\
\text { perpustakaan dapat memenuhi } \\
\text { kebutuhan belajar-mengajar } \\
\text { pada program studi }\end{array}$ & $\begin{array}{l}\text { 1) Menampung usulan pengadaan buku } \\
\text { 2) Jemput bola usulan pengadaan buku ke program studi }\end{array}$ \\
\hline 4 & $\begin{array}{l}\text { Kepuasan terhadap kemudahan } \\
\text { menemukan buku-buku dalam } \\
\text { rak-rak koleksi }\end{array}$ & $\begin{array}{l}\text { 1) Disediakan rambu -rambu sesuai nomor klasifikasi buku } \\
\text { di setiap rak } \\
\text { 2) Penataan koleksi sesuai kaidah yang benar }\end{array}$ \\
\hline 5 & $\begin{array}{l}\text { Kepuasan terhadap kepuasan } \\
\text { terhadap Keteraturan susunan } \\
\text { koleksi di rak }\end{array}$ & $\begin{array}{l}\text { 1) Shelving buku dilakukan minimal } 3 \text { kali dalam setiap hari } \\
\text { oleh Mitra Perpustakaan (mahasiswa partimer berjumlah } \\
30 \text { orang) } \\
\text { 2) Dilakukan pengecekan koleksi setiap hari Sabtu untuk } \\
\text { menjamin kebenaran shelving koleksi }\end{array}$ \\
\hline 6 & $\begin{array}{l}\text { Kepuasan terhadap kesesuaian } \\
\text { informasi pada sistem } \\
\text { penelusuran informasi digital } \\
\text { dengan koleksi yang tersedia }\end{array}$ & $\begin{array}{l}\text { 1) Dilakukan v erifikasi dan validasi pada data sebelum } \\
\text { di"release" pada sistem informasi } \\
\text { 2) Dilakukan pengecekan pada data-data lama } \\
\text { 3) Dilakukan pemantauan Produk Tidak Sesuai, jika } \\
\text { ditemukan kesalahan/ketidak sesuai pada sistem langsung } \\
\text { ditindaklanjuti. }\end{array}$ \\
\hline 7 & $\begin{array}{l}\text { Kepuasan terhadap kemudahan } \\
\text { dalam menelusur informasi pada } \\
\text { katalog penelusuran informasi } \\
\text { digital }\end{array}$ & $\begin{array}{l}\text { 1) Disediakan interface yang mudah } \\
\text { 2) Disediakan petunjuk secara jelas pada sistem informasi }\end{array}$ \\
\hline 8 & $\begin{array}{l}\text { Kepuasan terhadap kelengkapan } \\
\text { isi informasi pada sistem } \\
\text { penelusuran informasi digital di } \\
\text { perpustakaan }\end{array}$ & $\begin{array}{l}\text { Dilakukan verifikasi dan val idasi pada data sebelum } \\
\text { di"release" pada sistem informasi }\end{array}$ \\
\hline
\end{tabular}

Data primer diolah 2015 
Informasi dan sarana akses informasi selalu ditingkatkan dan dipertahankan kualitasnya oleh Perpustakaan USD. Perpustakaan USD memiliki Bagian Pelayanan Teknis yang menjalankan tugasnya berdasarkan Prosedur Pengembangan Koleksi (750/P/001) dan Prosedur Pengolahan Koleksi (750/P/002). Ke dua prosedur ini mengatur mengenai kualitas koleksi dan sarana akses informasi, sejak perencanaan pengadaan koleksi sampai pada ketersediaan koleksi yang mudah diakses oleh pemustaka. Dukungan pengembangan sistem informasi yang terkendali melalui Prosedur Desain dan Pengembangan Produk (730/P/001) dan pemeliharaan sistem yang dilakukan oleh Bagian Sarana Prasarana dan Sistem Informasi. Hal penting tersedianya dana pengembangan informasi dan sarana akses informasi yang dianggarkan secara rutin setiap tahunnya.

\subsection{Peningkatan Terhadap Pelayanan Perpustakaan \\ Tabel di bawah ini memaparkan mengenai berbagai upaya peningkatan yang dilakukan perpustakaan USD terkait berbagai butir pertanyaan mengenai pelayanan perpustakaan.}

Tabel. 4. Peningkatan terhadap Pelayanan Perpustakaan

\begin{tabular}{|c|c|c|}
\hline No. & Butir Pertanyaan & Tindaklanjut \\
\hline \multirow[t]{3}{*}{1} & $\begin{array}{l}\text { Kepuasan terhadap } \\
\text { pelayanan Locker }\end{array}$ & $\begin{array}{l}\text { 1) Disediakan prosedur pelayanan locker sehingga pelay anan di } \\
\text { locker dibakukan }\end{array}$ \\
\hline & & 2) Diberi pengarahan terhadap petugas locker \\
\hline & & $\begin{array}{l}\text { 3) Disediakan penambahan jumlah locker sesuai kebutuhan } \\
\text { pemustaka, misalnya locker dalam ukuran yang lebih besar }\end{array}$ \\
\hline \multirow[t]{2}{*}{ • } & & 4) Peminjaman locker secara mandiri menggunakan sistem \\
\hline & & $\begin{array}{l}\text { 5) Dilakukan pelatihan sumber daya manusia terkait dengan } \\
\text { pelayanan prima }\end{array}$ \\
\hline \multirow[t]{5}{*}{2} & $\begin{array}{l}\text { Kepuasan terhadap } \\
\text { pelayanan Sirkulasi }\end{array}$ & $\begin{array}{l}\text { 1) Disediakan prosedur pelayanan sirkulasi sehingga pelayanan } \\
\text { sirkulasi dibakukan }\end{array}$ \\
\hline & & 2) Diberi pengarahan dan sosialisasi terhadap petugas sirkulasi \\
\hline & & 3) Disediakan pelayanan peminjaman buku secara mandiri \\
\hline & & $\begin{array}{l}\text { 4) Disediakan fasilitas otentikasi/ password untuk peminjaman } \\
\text { koleksi }\end{array}$ \\
\hline & & $\begin{array}{l}\text { 5) Dilakukan pelatihan sumber daya manusia terkait dengan } \\
\text { pelayanan prima }\end{array}$ \\
\hline \multirow[t]{2}{*}{3} & Kepuasan terhadap & 1) Disediakan panduan dalam mencetak/fotokopi \\
\hline & $\begin{array}{l}\text { pelayanan Fotokopi dan } \\
\text { Cetak Digital? }\end{array}$ & $\begin{array}{l}\text { 2) Disediakan fasilitas fotokopi dan cetak digital di perpustakaan } \\
\text { dengan sistem outsourching }\end{array}$ \\
\hline \multirow[t]{4}{*}{4} & Kepuasan terhadap & 1) Akses workstation gratis \\
\hline & pelayanan Workstation & 2) Penambahan komputer dan jaringan di workstation \\
\hline & & 3) Penambahan titik akses hotspot \\
\hline & & $\begin{array}{l}\text { 4) Dilakukan pela tihan sumber daya manusia terkait dengan } \\
\text { pelayanan prima dan penguasaan komputer }\end{array}$ \\
\hline \multirow[t]{2}{*}{5} & Kepuasan terhadap & 1) Disediakan database jurnal online \\
\hline & pelayanan Majalah/Jurnal & $\begin{array}{l}\text { 2) Dilakukan pelatihan sumber daya manusia terkait dengan } \\
\text { pelayanan prima }\end{array}$ \\
\hline \multirow[t]{4}{*}{6} & Kepuasan terhadap & 1) Pelayanan informasi dilakukan di setiap titik pelayanan \\
\hline & pelayanan informasi & 2) Disediakan brosur perpustakaa \\
\hline & & 3) Disediakan paduan/rambu-rambu perpustakaan \\
\hline & & $\begin{array}{l}\text { 4) Dilakukan pelatihan sumber daya manusia terkait dengan } \\
\text { pelayanan prima }\end{array}$ \\
\hline \multirow[t]{2}{*}{7} & $\begin{array}{l}\text { Kepuasan terhadap jam } \\
\text { pelayanan perpustakaan }\end{array}$ & $\begin{array}{l}\text { 1) Jam pelayanan perpustakaan sudah dilakukan secara maksimal. } \\
\text { Senin - Jum'at pukul } 07.30-20.30 \text { dan hari Sabtu yang } \\
\text { seharusnya universitas libur, perpustakaan tetap buka pada } \\
\text { pukul } 07.30-12.30 \text { WIB. }\end{array}$ \\
\hline & & $\begin{array}{l}\text { 2) Apabila ada kegiatan yang melibatkan semua sta f perpustakaa, } \\
\text { perpustakaan tetap buka dengan mengandalkan petugas } \\
\text { partimer }\end{array}$ \\
\hline \multirow[t]{2}{*}{8} & $\begin{array}{l}\text { Kepuasan terhadap batas } \\
\text { maksimal jumlah }\end{array}$ & $\begin{array}{l}\text { 1) Perpustakaan mengedarkan kuesioner mengenai kebutuhan } \\
\text { /batas maksimal peminjaman buku }\end{array}$ \\
\hline & pinjaman buku & 2) Menambah batas pinjaman buku dari 6 menjadi 10 eksemplar \\
\hline
\end{tabular}


Pelayanan perpustakaan sebagai ujung tombak seluruh aktivitas perpustakaan selalu ditingkatkan dan dipertahankan kualitasnya oleh Perpustakaan USD. Perpustakaan USD memiliki Bagian Pelayanan Pengguna yang menjalankan tugasnya berdasarkan Prosedur Pelayanan Pengguna (750/P/003), dan didukung oleh Prosedur Pengembangan SDM (620/P/001). Ke dua prosedur tersebut mengatur mengenai bagaimana pelayanan perpustakaan yang baik dan terstandar, serta bagaimana peningkatan sumber daya manusia, termasuk dalam hal melayani kepada pemustaka.
Selain itu didukung oleh dana pengembangan pelayanan dan pengembagan sumber daya manusia yang dianggarkan secara rutin setiap tahunnya.

\subsection{Peningkatan terhadap Infrastruktur dan Lingkungan Kerja}

Tabel di bawah ini memaparkan mengenai berbagai upaya peningkatan yang dilakukan perpustakaan USD terkait berbagai butir pertanyaan mengenai infrastrutur dan lingkungan kerja.

Tabel. 5. Peningkatan terhadap Infrastruktur dan Lingkungan Kerja

\begin{tabular}{|c|c|c|}
\hline No. & Butir Pertanyaan & Tindaklanjut \\
\hline 1 & $\begin{array}{l}\text { Kepuasan terhadap } \\
\text { perabot }\end{array}$ & $\begin{array}{l}\text { - Penambahan rak, meja, kursi, sofa } \\
\text { - Kebersihan perabot perpustakaan selalu dilakukan oleh tenaga } \\
\text { outsourching perpustakaan }\end{array}$ \\
\hline 2 & $\begin{array}{l}\text { Kepuasan terhadap } \\
\text { kebersihan lantai }\end{array}$ & $\begin{array}{l}\text { - Kebersihan lantai perpustakaan selalu dilakukan oleh tenaga } \\
\text { outsourching perpustakaan } \\
\text { - Kinerja tenaga outsourching selalu dievaluasi untuk } \\
\text { peningkatan berkelanjutan }\end{array}$ \\
\hline 3 & $\begin{array}{l}\text { Kepuasan terhadap } \\
\text { kebersihan toilet }\end{array}$ & $\begin{array}{l}\text { - Kebersihan toilet perpustakaan selalu dilakukan oleh tenaga } \\
\text { outsourching perpustakaan } \\
\text { - Kinerja tenaga outsourching selalu dievaluasi untuk } \\
\text { peningkatan berkelanjutan }\end{array}$ \\
\hline 4 & $\begin{array}{l}\text { Kepuasan terhadap } \\
\text { kenyamanan ruang }\end{array}$ & $\begin{array}{l}\text { - Perpustakaan menyediakan batas ruang yang jelas di mana } \\
\text { orang bisa berdiskusi atau belajar mandiri } \\
\text { - Disediakan sofa di titik - titik pelayanan sehingga membuat } \\
\text { nyaman pemustaka } \\
\text { - Fasilitas AC, penerangan, taman selalu dilakukan perawatan } \\
\text { sehingga membuat nyaman pemustaka }\end{array}$ \\
\hline
\end{tabular}

Infrastruktur dan lingkungan kerja juga selalu ditingkatkan dan dipertahankan kualitasnya oleh Perpustakaan USD. Perpustakaan USD memiliki Bagian Sarana Prasarana dan Sistem Informasi yang menjalankan tugasnya berdasarkan Prosedur Infrastruktur dan Lingkungan Kerja (630/P/001). Prosedur ini digunakan di setiap bagian di lingkungan PUSD sebagai petunjuk dalam menetapkan, menyediakan, mengelola dan memelihara infrastruktur dan lingkungan kerja. Dengan prosedur ini keberadaan gedung, sarana prasarana dan lingkungan kerja di Perpustakaan USD dikelola dan dipelihara dengan baik. Selain itu tentu juga didukung oleh dana pengembangan infrastruktur dan lingkungan kerja yang dianggarkan secara rutin setiap tahun.

\section{KESIMPULAN}

Secara umum, hasil penelitian menunjukkan bahwa hasil pemantauan dan pengukuran sasaran mutu kepuasan pemustaka di Perpustakaan Universitas Sanata Dharma selama kurun waktu tahun 2008 s.d. 2014 mencapai target yang ditentukan, yaitu berkisar antara 3,5 s.d. 3,8 pada skala $1-5$.

Hasil pemantauan dan pengukuran kepuasan pemustaka juga memberikan gambaran yang dapat digunakan untuk menganalisis ketercapaian kepuasan pemustaka. Data diambil dari alasan atau masukan yang diberikan oleh responden. Alasan atau masukan tersebut, selanjutnya dikumpulkan dan dianalisis, di titik mana bisa memberikan masukan untuk peningkatan berkelanjutan. Perpustakaan selanjutnya 
melakukan tindak lanjut terhadap informasi dan akses informasi, pelayanan perpustakaan dan infrastruktur dan lingkungan kerja.

Peningkatan akses informasi dilakukan melalui: 1. Pembuatan formulir usulan buku secara online; 2 . Penambahan judul-judul buku berdasarkan inisiatif perpustakaan; 3. Pengadaan judul buku yang tidak dimiliki perpustakaan dari hasil pemantauan sasaran mutu ketersediaan koleksi; 4. Penyediaan jumlah eksemplar buku sesuai dengan dokumen Kebijakan Pengembangan Koleksi $(750 / \mathrm{D} / 101) ; 5$. Penambahan eksemplar buku dengan tingkat peminjaman tinggi; 6 . Menerima usulan pengadaan buku; 7. Jemput bola usulan pengadaan buku ke program studi; 8 . Pemasangan rambu-rambu sesuai nomor klasifikasi buku di setiap rak; 9. Penataan koleksi sesuai kaidah yang benar; 10 . Shelving buku dilakukan minimal 3 kali dalam setiap hari oleh Mitra Perpustakaan (mahasiswa partimer berjumlah 30 orang); 11. Pengecekan koleksi setiap hari Sabtu untuk menjamin kebenaran shelving koleksi; 12. Verifikasi dan validasi pada data sebelum di"release" pada sistem informasi; 13.Pemantauan Produk Tidak Sesuai, jika ditemukan kesalahan/ketidaksesuaian pada sistem, langsung ditindaklanjuti; 14. Penyediaan interface yang mudah; 15. Penyediaan petunjuk secara jelas pada sistem informasi.

Peningkatan pelayanan perpustakaan dilakukan melalui: 1. Penyediaan prosedur pelayanan locker sehingga pelayanan di locker dibakukan; 2. Pemberian pengarahan terhadap petugas locker; 3 . Penambahan jumlah locker sesuai kebutuhan pemustaka, misalnya locker dalam ukuran yang lebih besar; 4. Peminjaman locker secara mandiri menggunakan sistem; 5. Pelatihan sumber daya manusia terkait dengan pelayanan prima; 6 . Penyediaan prosedur pelayanan sirkulasi sehingga pelayanan sirkulasi dibakukan; 7. Pemberian pengarahan dan sosialisasi terhadap petugas sirkulasi; 8. Penyediaan pelayanan peminjaman buku secara mandiri; 9. Penyediaan fasilitas otentikasi/ password untuk peminjaman koleksi; 10. Penyediaan panduan dalam mencetak/fotokopi; 11. Penyediaan fasilitas fotokopi dan cetak digital dengan sistem outsourching; 12. Akses workstation gratis; 13. Penambahan komputer dan jaringan di workstation; 14. Penambahan titik akses hotspot; 15. Penyediaan database jurnal online; 16. Pelayanan informasi yang dilakukan di setiap titik pelayanan; 17. Penyediaan brosur perpustakaan; 18. Penyediaan paduan/rambu-rambu perpustakaan; 19. Pemberian jam pelayanan perpustakaan secara maksimal. Senin - Jum'at pukul 07.30 - 20.30 dan hari Sabtu yang seharusnya universitas libur, perpustakaan tetap buka pada pukul $07.30-12.30$ wib.; 20 . Apabila ada kegiatan yang melibatkan semua staf perpustakaan, perpustakaan tetap buka dengan sumber daya petugas partimer; 21. Pemberian edaran kuesioner mengenai kebutuhan/batas maksimal peminjaman buku; 22. Penambahan batas pinjaman buku dari 6 menjadi 10 eksemplar.

Peningkatan infrastruktur dan lingkungan kerja melalui: 1. Penambahan rak, meja, kursi, sofa; 2. Kebersihan perpustakaan yang selalu dilakukan oleh tenaga outsourching perpustakaan; 3. Evaluasi kinerja tenaga outsourching untuk peningkatan berkelanjutan; 4 . Penyediaan batas ruang yang jelas di mana orang bisa berdiskusi atau belajar mandiri; 5 . Penyediaan sofa di titik-titik pelayanan sehingga membuat nyaman pemustaka; 6. Perawatan fasilitas $\mathrm{AC}$, penerangan, dan taman sehingga membuat nyaman pemustaka.

\section{DAFTAR PUSTAKA:}

Gerson, Richard F. 2002. Mengukur Kepuasan Pelanggan, Cetakan kedua, Jakarta: PPM.

Nazir, Moh. 2005. Metode Penelitian. Bogor: Ghalia Indonesia.

Perpustakaan Nasional Republik Indonesia, 2004. Pedoman Umum Penyelenggaraan Perpustakaan Perguruan Tinggi, Jakarta: Perpustakaan Nasional Republik Indonesia.

Perpustakaan USD. 2012. Dokumen Mutu ISO 9001:2008.

Rahayuningsib (Ed). 2007. Pengelolaan Perpustakaan. Yogyakarta: Graha Ilmu.

2015. Mengukur Kepuasan Pemustaka Menggunakan Metode Libqual+Tm. Yogyakarta: Graha Ilmu. 